\title{
REQUERIMENTO, ACÚMULO E DISTRIBUIÇÃO DE MACRONUTRIENTES EM MUDAS DE PINHÃO-MANSO
}

\author{
Luís Paulo Patente Tanure ${ }^{1}$, Enilson de Barros Silva² ${ }^{2}$ Gustavo Antônio Mendes Pereira ${ }^{3}$, \\ Bárbara Olinda Nardis ${ }^{4}$, Evander Alves Ferreira ${ }^{5}$
}

1 Doutor em Solos e Nutrição de Plantas, Universidade Federal de Viçosa, Viçosa-MG. E-mail: luis.tanure@produquimica.com.br

${ }^{2}$ Doutor em Ciência do Solo, Professor Associado da Universidade Federal dos Vales do Jequitinhonha e Mucuri, Diamantina-MG. E-mail: enilson.barros.silva@gmail.com

${ }^{3}$ Doutor em Fitotecnia pela Universidade Federal de Viçosa, Viçosa-MG. *E-mail: gustavogamp@ hotmail.com

4 Doutoranda em Ciência do Solo na Universidade Federal de Lavras, Lavras-MG. E-mail: barbara.olinda@yahoo.com.br

${ }^{5}$ Doutor em Fitotecnia, Universidade Federal dos Vales do Jequitinhonha e Mucuri, Diamantina-MG. E-mail: evanderalves@gmail.com

RESUMO: O objetivo deste trabalho foi avaliar as exigências nutricionais de mudas de pinhão-manso, bem como o acúmulo e a distribuição de macronutrientes nas diferentes partes da planta, em condições de casa de vegetação. Os tratamentos consistiram de solução nutritiva completa e com omissão de $\mathrm{N}, \mathrm{P}, \mathrm{K}, \mathrm{Ca}, \mathrm{Mg}$ e $\mathrm{S}$, pelo uso da técnica do elemento faltante. Após 100 dias, foram avaliados, a massa seca das partes da planta e os teores de macronutrientes na massa seca. O pinhão-manso se mostrou altamente exigente em macronutrientes e o requerimento se apresentou na seguinte sequência: $\mathrm{N}>\mathrm{Ca}>\mathrm{K}>\mathrm{P}>\mathrm{Mg}$ $>\mathrm{S}$. Porém, com as menores taxas de produção de massa seca nas omissões de $\mathrm{Ca}$ e de $\mathrm{K}$. A folha completa apresentou os maiores acúmulos de nutrientes entre as partes do pinhão-manso e o $\mathrm{N}$ foi o mais acumulado entre as partes analisadas. Demonstrando, dessa forma, altas demandas por $\mathrm{N}, \mathrm{P}$ e K.

Palavras-chave: Jatropha curcas L. Oleaginosa. Nutrição mineral. Elemento faltante. Solução nutritiva.

\section{NUTRITIONAL REQUERIMENT, ACCUMULATION AND DISTRIBUTION OF MACRONUTRIENTS IN PHYSIC NUT SEEDLINGS}

\begin{abstract}
The objective of this work was to evaluate the nutritional requirements of jatropha seedlings, as well as the accumulation and distribution of macronutrients in different parts of the plant under greenhouse conditions. The treatments consisted of complete nutrient solution and with omission of $\mathrm{N}, \mathrm{P}, \mathrm{K}, \mathrm{Ca}, \mathrm{Mg}$ and $\mathrm{S}$, by the use of the missing element technique. After 100 days, the dry mass of the plant parts and the macronutrient contents of the dry mass were evaluated. Jatropha was highly demanding on macronutrients and the requirement was presented in the following sequence: $\mathrm{N}>\mathrm{Ca}>\mathrm{K}>\mathrm{P}>\mathrm{Mg}>\mathrm{S}$. However, with the lowest rates of dry mass production in the omissions of $\mathrm{Ca}$ and $\mathrm{K}$. The complete leaf presented the greatest accumulations of nutrients between the parts of the Jatropha and $\mathrm{N}$ was
\end{abstract}

Cultura Agronômica, Ilha Solteira, v.26, n.3, p.443-455, 2017 
the most accumulated among the analyzed parts. Demonstrating, thus, high demands for N, P and $\mathrm{K}$.

Key words: Jatropha curcas L. Oleaginous. Mineral nutrition. Missing element. Nutrient solution.

\section{INTRODUÇÃO}

O pinhão-manso (Jatropha curcas L.) é uma espécie da família Euphorbiaceae que passou a ser conhecida com o advento do biodiesel, devido ao seu potencial na produção de óleo (NUNES, 2007). Seu centro de origem, domesticação e diversidade ainda é bastante discutido e controverso (AMBROSI et al., 2010; CHEN et al., 2011; WANG et al., 2009), porém, alguns autores consideram que o Brasil seja o centro de origem da espécie (OVANDOMEDINA et al., 2011).

O pinhão-manso é tido como cultura rústica, adaptada às mais diversas condições edafoclimáticas, sobrevivendo bem em solos com condições precárias quanto à fertilidade natural. Pode ser cultivado em solos, arenosos, salinos e crescer em fissuras de rochas, por exemplo (SINGH et al., 2007), condições estas, tidas como adversas para muitas culturas. No entanto, uma grande quantidade de nutrientes é extraída do solo com a colheita dos frutos de pinhão-manso, podendo ocorrer empobrecimento do solo ao longo dos anos de cultivo se estes não forem adequadamente repostos pela adubação (LAVIOLA; DIAS, 2008). Portanto, embora tenha alta capacidade adaptativa às adversidades edafoclimáticas, tem se observado que há necessidade de certo nível tecnológico, principalmente com relação à fertilidade do solo, para que seja alcançada uma alta produtividade de frutos de pinhão-manso (OLIVEIRA et al., 2012).

O pinhão-manso se tornou, portanto, uma espécie vegetal bastante utilizada, mas cujas características de crescimento e desenvolvimento, aliadas às suas necessidades nutricionais ainda merecem estudos.

Visando sanar a necessidade de informações sobre os requerimentos nutricionais de espécies vegetais, Malavolta (2006) indicou a utilização de soluções nutritivas. Segundo esse autor, experimentos com plantas em solução nutritiva têm permitido avanços no conhecimento da nutrição das plantas, pois possibilitam um controle na quantidade de nutrientes, eliminando a heterogeneidade e complexidade de fatores como $\mathrm{pH}$ do solo, entre outros, como os realizados por Maia et al. (2014) em pinhão-manso, por Neves et al. (2005) em girassol e por Dias et al. (2010) em melão.

Portanto, para suprir adequadamente as necessidades nutricionais de qualquer espécie, é necessário, antes, ter conhecimento do efeito que cada nutriente, quando ausente, provoca no seu crescimento e desenvolvimento. Sendo assim, o presente trabalho teve por objetivo avaliar as exigências nutricionais de mudas de pinhão-manso, bem como o acúmulo e a distribuição de macronutrientes nas diferentes partes da planta.

Cultura Agronômica, Ilha Solteira, v.26, n.3, p.443-455, 2017 


\section{MATERIAL E MÉTODOS}

O experimento foi conduzido em condições de casa de vegetação, no campus JK da Universidade Federal dos Vales do Jequitinhonha e Mucuri, no município de Diamantina, situada nas coordenadas de $18^{\circ} 15^{\prime}$ de latitude sul e $43^{\circ} 36^{\prime}$ de longitude Oeste e altitude 1.400 $\mathrm{m}$.

Inicialmente, as sementes de pinhão-manso foram germinadas em bandejas em areia fina, previamente esterilizadas em estufa a $50{ }^{\circ} \mathrm{C}$, por 48 horas. Após 21 dias da germinação, as mudas foram transplantadas para vasos de 4 litros (altura $=17 \mathrm{~cm}$; diâmetro superior $=21$ $\mathrm{cm}$ e diâmetro inferior $=17 \mathrm{~cm}$ ), preenchidos com solução nutritiva completa de Hoagland e Arnon (1950), diluída para 25\% durante 72 horas, somente com macronutrientes (3 litros), para o período de adaptação.

Após esse período, a solução completa de Hoagland e Arnon teve sua concentração aumentada para 50\% da concentração, ficando as mudas por período igual de adaptação em aeração constante, por meio de um compressor de ar comprimido. Ao fim da adaptação, as mudas foram transplantadas para os vasos de mesmas dimensões contendo a solução nutritiva nos tratamentos testados. $\mathrm{O}$ transplantio definitivo das mudas para o vaso ocorreu quando as mesmas possuíam diâmetro médio de 7,8 $\mathrm{mm}$ e altura média de $16,5 \mathrm{~cm}$, aos 30 dias após a germinação.

$\mathrm{O}$ experimento foi instalado em delineamento inteiramente casualizado, com sete tratamentos e quatro repetições. Os tratamentos foram constituídos pela solução completa de Hoagland e Arnon (1950) e por seis soluções com a omissão individual (-N; -P; -K; -Ca; -Mg e -S). Os nutrientes foram aplicados na forma de reagentes p.a., diluídos em água deionizada. A unidade experimental constituiu-se de um vaso com capacidade para 4,0 L, preenchido por 3,0 L de solução nutritiva, sendo uma planta por vaso.

As plantas receberam aeração constante, por meio de um compressor de ar comprimido durante a fase experimental, promovendo a reposição diária da água evapotranspirada, com a utilização de água destilada, ajustando o pH para 6,0. A solução foi renovada a cada 10 dias para reposição dos nutrientes.

Após o período experimental de 100 dias, as plantas foram retiradas dos vasos, seccionadas em parte aérea e raiz, sendo que, a parte aérea correspondeu às subsecções em limbo foliar, pecíolo, folha completa (limbo foliar + pecíolo) e caule. Esse material foi levado, separadamente, para a estufa de circulação forçada de ar a $65^{\circ} \mathrm{C}$ até peso constante, para avaliação posterior da massa seca. Desse material seco realizaram-se as determinações dos teores de macronutrientes, segundo metodologia descrita por Malavolta et al. (1997). Os teores foliares foram convertidos em conteúdo de macronutrientes na massa seca das diferentes partes das mudas de pinhão-manso.

Os dados obtidos foram submetidos à análise de variância, e as médias comparadas pelo teste de Scott \& Knott a 5\% utilizando o software Sisvar ${ }^{\circledR}$ 5.6. 


\section{RESULTADOS E DISCUSSÃO}

A menor produção de massa seca em folha completa foi observada sob omissão de Ca e omissão de K, com redução de $98,48 \%$ e $96,04 \%$ em relação ao tratamento completo, respectivamente (Tabela 1). Resultado que pode ter sido observado porque o macronutriente Ca é essencial para o crescimento de meristemas, responsável pelo crescimento das mudas, e está presente na sua fração principal nas paredes celulares ou nos vacúolos e organelas, exercendo papel estrutural ao manter a integridade da membrana citoplasmática (MATOH; KOBAYASHI, 1998). Enquanto o K atua como ativador enzimático e participa de processos como abertura de estômatos, fotossíntese, transporte de carboidratos e respiração (SHIMAZAKI et al., 2007). A deficiência de potássio induz o menor crescimento, tanto da parte aérea como das raízes. Os sintomas foliares caracterizam-se por clorose marginal das folhas, de modo irregular, que progride para necrose e expande-se para o centro da folha (SILVA et al., 2009). Maia et al. (2014), observaram que a omissão de potássio reduziu a área foliar, o número de folhas e a massa de matéria seca de folhas, o comprimento, o diâmetro e a massa de matéria seca do caule, o volume e a massa de matéria seca de raízes de plantas de pinhão-manso, assim como o observado no presente estudo.

Tabela 1. Produção de massa seca (g) das partes aérea (limbo foliar, pecíolo, folha completa, caule), raízes e total de mudas de pinhão-manso submetidas às aplicações de soluções nutritivas completa e faltantes.

\begin{tabular}{|c|c|c|c|c|c|c|c|c|c|c|c|c|c|c|}
\hline Tratamento & $\begin{array}{l}\text { Limbc } \\
\text { foliar }\end{array}$ & & Pecíol & & $\begin{array}{l}\text { Folha } \\
\text { comple }\end{array}$ & & Caule & & $\begin{array}{l}\text { Parte } \\
\text { aérea }\end{array}$ & & Raíze & & Total & \\
\hline Completo & 5,17 & b & 1,39 & $\mathrm{a}$ & 6,56 & $\mathrm{~b}$ & 13,11 & $\mathrm{a}$ & 19,67 & $\mathrm{a}$ & 3,31 & b & 22,98 & $\mathrm{a}$ \\
\hline$-\mathrm{N}$ & 0,52 & d & 0,09 & c & 0,61 & d & 2,23 & c & 2,84 & d & 0,51 & c & 3,35 & c \\
\hline$-\mathrm{P}$ & 0,42 & $\mathrm{~d}$ & 0,01 & $c$ & 0,43 & d & 0,67 & $\mathrm{~d}$ & 1,10 & $\mathrm{e}$ & 0,38 & c & 1,48 & d \\
\hline$-\mathrm{K}$ & 0,25 & $\mathrm{e}$ & 0,01 & c & 0,26 & e & 0,72 & d & 0,98 & e & 0,13 & d & 1,11 & d \\
\hline$-\mathrm{Ca}$ & 0,08 & e & 0,02 & c & 0,10 & $\mathrm{e}$ & 0,40 & e & 0,50 & $f$ & 0,05 & d & 0,55 & d \\
\hline$-\mathrm{Mg}$ & 2,29 & $\mathrm{c}$ & 0,27 & b & 2,57 & c & 0,91 & d & 3,48 & $\mathrm{c}$ & 0,51 & c & 3,99 & c \\
\hline$-S$ & 6,92 & $\mathrm{a}$ & 1,45 & $\mathrm{a}$ & 8,38 & $\mathrm{a}$ & 6,92 & b & 15,30 & b & 3,48 & $\mathrm{a}$ & 18,78 & b \\
\hline $\mathrm{CV}(\%)$ & \multicolumn{2}{|l|}{6,82} & \multicolumn{2}{|c|}{15,63} & \multicolumn{2}{|l|}{2,98} & \multicolumn{2}{|l|}{4,09} & \multicolumn{2}{|l|}{4,43} & \multicolumn{2}{|c|}{18,45} & \multicolumn{2}{|l|}{8,43} \\
\hline
\end{tabular}

Médias seguidas de mesma letra, na coluna, não diferem entre si pelo teste de Scott \& Knott a 5\%.

Em relação aos demais tratamentos, observou-se que, para produção de massa seca da folha completa, as omissões de $\mathrm{P}$, de $\mathrm{N}$ e de $\mathrm{Mg}$ (Tabela 1) apresentaram, respectivamente, reduções de 93,45\%; 90,70\% e 60,82\% em relação ao tratamento completo. Apesar de ser uma planta bem adaptada à solos de baixa fertilidade, como os tropicais, as mudas de pinhãomanso têm se mostrado responsivas à adubação fosfatada, como o observado por Lima et al. (2011) que verificaram que a aplicação de fertilizante fosfatado propiciou o crescimento principalmente de raízes e área foliar e também o aumento no tecido vegetal e no teor de todos os macronutrientes em pinhão-manso. Os resultados obtidos para a omissão com P está ligada às funções do elemento na planta, como seu papel na fotossíntese, respiração, armazenamento e transferência de energia, divisão e crescimento celular (TAIZ; ZEIGER, 2013). Assim, a

Cultura Agronômica, Ilha Solteira, v.26, n.3, p.443-455, 2017 
deficiência de $\mathrm{P}$ reduz o processo metabólico, afetando o crescimento das mudas e, por consequência, a produção de massa seca.

A maior produção de massa seca para folha completa foi observada nas mudas submetidas ao tratamento no qual se omitiu o $S$ (Tabela 1). Ressalta-se que a omissão de $S$ não reduziu o crescimento das folhas das mudas de pinhão-manso, havendo um ganho de $27,74 \%$ da massa seca da folha completa em relação ao tratamento completo (Tabela 1). Resultados semelhantes foram encontrados por Batista et al. (2003), quando a cultura da graviola (Annona muricata) apresentou maior produção de massa seca da folha em tratamentos sob omissão do S, proporcionando maior produção que o tratamento completo.

A produção de massa seca do caule foi reduzida na omissão dos macronutrientes, sendo a maior redução na omissão de Ca (Tabela 1), que foi de $96,95 \%$ em relação ao tratamento completo.

Seguindo a mesma tendência da folha completa, a parte aérea sofreu maior redução na produção de massa seca, quando as mudas de pinhão-manso foram submetidas à omissão de Ca (Tabela 1), apresentando decréscimo de 97,46\% em relação ao tratamento completo. A falta de Ca é caracterizada pela redução do crescimento de tecidos meristemáticos, sendo observada, primeiramente, nas extremidades (MATOH; KOBAYASHI, 1998). Resultados semelhantes foram encontrados por Lavres Júnior et al. (2005), para a mamona cultivar Íris.

A produção de massa seca do sistema radicular foi severamente afetada pela omissão de $\mathrm{Ca}$ e de $\mathrm{K}$, contrariamente à omissão de $\mathrm{S}$, que proporcionou a maior produção de massa seca, semelhantemente ao que ocorreu em outras partes das plantas e isso demonstrou uma baixa exigência pelo elemento nessa fase de crescimento (Tabela 1). Nesse caso, os tratamentos com omissão Ca e K apresentaram reduções de 98,49 e 96,07\%, respectivamente, em relação ao tratamento completo. Resultados similares foram encontrados por Marques et al. (2004) em mudas de paricá (Schizolobium amazonicum), quando as plantas sob omissão de Ca sofreram redução no crescimento do sistema radicular em função da baixa translocação do Ca na planta, uma vez que os sintomas de deficiência do nutriente ocorrem nos pontos de crescimento da parte aérea e raiz, afetando a expansão celular.

Em trabalho realizado por Maia et al. (2014) a omissão de Ca em plantas de pinhãomanso reduziu significativamente, a área foliar, o número de folhas e a massa de matéria seca de folhas; o comprimento e a massa seca do caule; o comprimento, o volume e a massa seca das raízes. Os autores afirmaram que o volume radicular, a área foliar e a produção de massa seca de raízes foram as características biométricas mais afetadas pela omissão de $\mathrm{Ca}$, com reduções de 64, 62 e 57\%, comparativamente às das plantas do tratamento completo, situação semelhante ao ocorrido no presente estudo.

As mudas de pinhão-manso apresentaram elevada exigência nutricional, apresentando melhor resposta de massa seca total sob tratamento completo (Tabela 1), dados que apresentaram diferenças significativas em relação a todos os tratamentos com omissão. As

Cultura Agronômica, Ilha Solteira, v.26, n.3, p.443-455, 2017 
omissões de $\mathrm{Ca}, \mathrm{K}$ e $\mathrm{P}$ apresentaram menores produções de massa seca em relação ao tratamento completo na ordem de $97,61 \% ; 95,17 \%$ e $93,56 \%$, respectivamente.

Tabela 2. Acúmulo de macronutrientes $\left(\mathrm{mg} \mathrm{vaso}^{-1}\right)$ em diferentes partes foliares de mudas de pinhão-manso submetidas às aplicações de soluções nutritivas completa e faltantes

\begin{tabular}{|c|c|c|c|c|c|c|c|}
\hline Tratamento & $\mathrm{N}$ & $\mathrm{P}$ & $\mathrm{K}$ & $\mathrm{Ca}$ & & $\mathrm{Mg}$ & $\mathrm{S}$ \\
\hline \multicolumn{8}{|c|}{ Limbo foliar. } \\
\hline Completo & $224,88 \mathrm{~b}$ & 44,06 a & $109,06 \mathrm{~b}$ & 102,33 & $\mathrm{a}$ & $35,32 \mathrm{~b}$ & $14,61 \mathrm{a}$ \\
\hline$-\mathrm{N}$ & $12,48 \mathrm{~d}$ & $1,04 \mathrm{c}$ & $23,85 \mathrm{~d}$ & 14,83 & $\mathrm{c}$ & $5,80 \mathrm{c}$ & $1,68 \mathrm{~d}$ \\
\hline$-\mathrm{P}$ & $15,16 \mathrm{~d}$ & $0,56 \mathrm{c}$ & $32,32 \mathrm{~d}$ & 7,56 & d & $2,73 \mathrm{~d}$ & $2,28 \mathrm{~d}$ \\
\hline$-\mathrm{K}$ & $14,00 \mathrm{~d}$ & $3,42 \mathrm{c}$ & $21,45 \mathrm{~d}$ & 8,93 & d & $2,53 \mathrm{~d}$ & $1,42 \mathrm{~d}$ \\
\hline$-\mathrm{Ca}$ & $8,00 \mathrm{~d}$ & $1,08 \mathrm{c}$ & $2,25 \mathrm{e}$ & 0,24 & $\mathrm{e}$ & $0,62 \mathrm{~d}$ & $0,29 \mathrm{e}$ \\
\hline$-\mathrm{Mg}$ & $102,08 \mathrm{c}$ & $18,64 \mathrm{~b}$ & $67,47 \mathrm{c}$ & 37,24 & b & $1,54 \mathrm{~d}$ & $5,84 \mathrm{c}$ \\
\hline$-S$ & 293,86 a & $23,62 \mathrm{~b}$ & $178,11 \mathrm{a}$ & 105,77 & $\mathrm{a}$ & 58,30 a & $12,27 \mathrm{~b}$ \\
\hline $\mathrm{CV}(\%)$ & 8,38 & 20,56 & 19,90 & 8,83 & & 13,00 & 14,48 \\
\hline \multicolumn{8}{|c|}{ Pecíolo .. } \\
\hline Completo & 27,95 a & $5,68 \mathrm{~b}$ & $4,33 \mathrm{c}$ & 23,48 & $\mathrm{a}$ & $3,02 \mathrm{~b}$ & $1,80 \mathrm{~b}$ \\
\hline$-\mathrm{N}$ & $0,90 \mathrm{~d}$ & $0,05 \mathrm{~d}$ & $1,20 \mathrm{~d}$ & 0,74 & $d$ & $0,29 \mathrm{c}$ & $0,08 \mathrm{~d}$ \\
\hline$-\mathrm{P}$ & $0,25 \mathrm{~d}$ & $0,00 \mathrm{~d}$ & $0,23 \mathrm{~d}$ & 0,06 & d & $0,02 \mathrm{c}$ & $0,02 \mathrm{~d}$ \\
\hline$-K$ & $0,40 \mathrm{~d}$ & $0,04 \mathrm{~d}$ & $0,25 \mathrm{~d}$ & 0,10 & d & $0,03 \mathrm{~d}$ & $0,02 \mathrm{~d}$ \\
\hline$-\mathrm{Ca}$ & $1,10 \mathrm{~d}$ & $0,12 \mathrm{~d}$ & $0,25 \mathrm{~d}$ & 0,03 & d & $0,07 \mathrm{~d}$ & $0,03 \mathrm{~d}$ \\
\hline$-\mathrm{Mg}$ & $4,95 \mathrm{c}$ & $2,88 \mathrm{c}$ & $22,63 \mathrm{~b}$ & 12,23 & $\mathrm{c}$ & $0,05 \mathrm{c}$ & $0,69 \mathrm{c}$ \\
\hline$-S$ & $19,95 \mathrm{~b}$ & 8,86 a & 38,35 a & 19,44 & $\mathrm{~b}$ & 4,07 a & $4,92 \mathrm{a}$ \\
\hline $\mathrm{CV}(\%)$ & 10,87 & 11,06 & 7,33 & 16,75 & & 19,87 & 6,63 \\
\hline \multicolumn{8}{|c|}{....... Folha completa } \\
\hline Completo & $252,83 \mathrm{~b}$ & 49,74 a & $113,40 \mathrm{~b}$ & 125,81 & a & $38,34 \mathrm{~b}$ & 16,40 a \\
\hline$-\mathrm{N}$ & $13,38 \mathrm{~d}$ & $1,09 \mathrm{~d}$ & $25,05 \mathrm{~d}$ & 15,57 & $\mathrm{c}$ & $6,09 \mathrm{c}$ & $1,77 \mathrm{~d}$ \\
\hline$-\mathrm{P}$ & $15,41 \mathrm{~d}$ & $0,56 \mathrm{~d}$ & $32,54 \mathrm{~d}$ & 7,62 & $\mathrm{c}$ & $2,75 \mathrm{~d}$ & $2,29 \mathrm{c}$ \\
\hline$-K$ & $14,40 \mathrm{~d}$ & $3,46 \mathrm{~d}$ & $21,70 \mathrm{~d}$ & 9,03 & $\mathrm{c}$ & $2,55 \mathrm{~d}$ & $1,43 \mathrm{~d}$ \\
\hline$-\mathrm{Ca}$ & $9,10 \mathrm{~d}$ & $1,20 \mathrm{~d}$ & $2,50 \mathrm{e}$ & 0,27 & d & $0,69 \mathrm{~d}$ & $0,32 \mathrm{e}$ \\
\hline$-\mathrm{Mg}$ & $107,03 \mathrm{c}$ & $21,52 \mathrm{c}$ & $90,09 \mathrm{c}$ & 49,46 & $\mathrm{~b}$ & $1,60 \mathrm{~d}$ & $6,52 \mathrm{~b}$ \\
\hline$-\mathrm{S}$ & 305,30 a & $31,48 \mathrm{~b}$ & $216,45 \mathrm{a}$ & 125,20 & $\mathrm{a}$ & 62,36 a & $17,18 \mathrm{a}$ \\
\hline $\mathrm{CV}(\%)$ & 8,56 & 18,61 & 16,22 & 9,10 & & 12,90 & 12,98 \\
\hline \multicolumn{8}{|c|}{ Caule . } \\
\hline Completo & $170,18 \mathrm{~b}$ & 38,40 a & 202,53 a & 82,37 & $\mathrm{~b}$ & $17,20 \mathrm{~b}$ & $17,98 \mathrm{a}$ \\
\hline$-\mathrm{N}$ & $16,14 \mathrm{e}$ & $9,28 \mathrm{c}$ & $64,07 \mathrm{~b}$ & 27,47 & $\mathrm{c}$ & $9,17 \mathrm{c}$ & $6,49 \mathrm{~d}$ \\
\hline$-\mathrm{P}$ & $18,33 \mathrm{e}$ & $0,76 \mathrm{~d}$ & $24,17 \mathrm{c}$ & 5,14 & $\mathrm{e}$ & $2,52 \mathrm{~d}$ & $3,01 \mathrm{f}$ \\
\hline$-\mathrm{K}$ & $36,20 \mathrm{c}$ & $10,05 \mathrm{c}$ & $10,23 \mathrm{c}$ & 14,46 & d & $8,04 \mathrm{c}$ & $3,98 \mathrm{e}$ \\
\hline$-\mathrm{Ca}$ & $25,60 \mathrm{~d}$ & $2,37 \mathrm{~d}$ & $28,80 \mathrm{c}$ & 0,65 & $\mathrm{e}$ & $2,77 \mathrm{~d}$ & $2,07 \mathrm{f}$ \\
\hline$-\mathrm{Mg}$ & $24,61 \mathrm{~d}$ & $5,81 \mathrm{e}$ & $19,65 \mathrm{c}$ & 22,67 & $\mathrm{c}$ & $0,83 \mathrm{~d}$ & $10,16 \mathrm{c}$ \\
\hline$-\mathrm{S}$ & 293,86 a & $23,99 \mathrm{~b}$ & $191,13 \mathrm{a}$ & 106,49 & $\mathrm{a}$ & 58,66 a & $12,27 \mathrm{~b}$ \\
\hline $\mathrm{CV}(\%)$ & 6,35 & 15,79 & 13,27 & 15,05 & & 13,22 & 9,1 \\
\hline
\end{tabular}

Médias seguidas de mesma letra, na coluna, não diferem entre si pelo teste de Scott \& Knott a 5\%.

Cultura Agronômica, Ilha Solteira, v.26, n.3, p.443-455, 2017 
Os maiores acúmulos de nutrientes nas diferentes partes estudadas das mudas de pinhão-manso ocorreram de forma a acompanhar as maiores produções de massa seca (Tabelas 2 e 3). Na parte aérea, o maior acúmulo de macronutrientes foi observado na folha completa, mesmo havendo menor produção de massa seca em relação ao caule (Tabela 2). Isso é explicado pelo fato de $\mathrm{N}, \mathrm{P}, \mathrm{K}$ e Mg apresentarem mobilidade dentro das plantas, sendo transportados, via xilema, até as folhas, para participarem do processo fotossintético (TAIZ; ZEIGER, 2013), o que é vital para o crescimento adequado das mudas, inclusive as de pinhãomanso.

Tabela 3. Acúmulo de macronutrientes $\left(\mathrm{mg} \mathrm{vaso}^{-1}\right)$ na parte aérea, raízes e total de mudas de pinhão-manso submetidas às aplicações de soluções nutritivas completa e faltantes

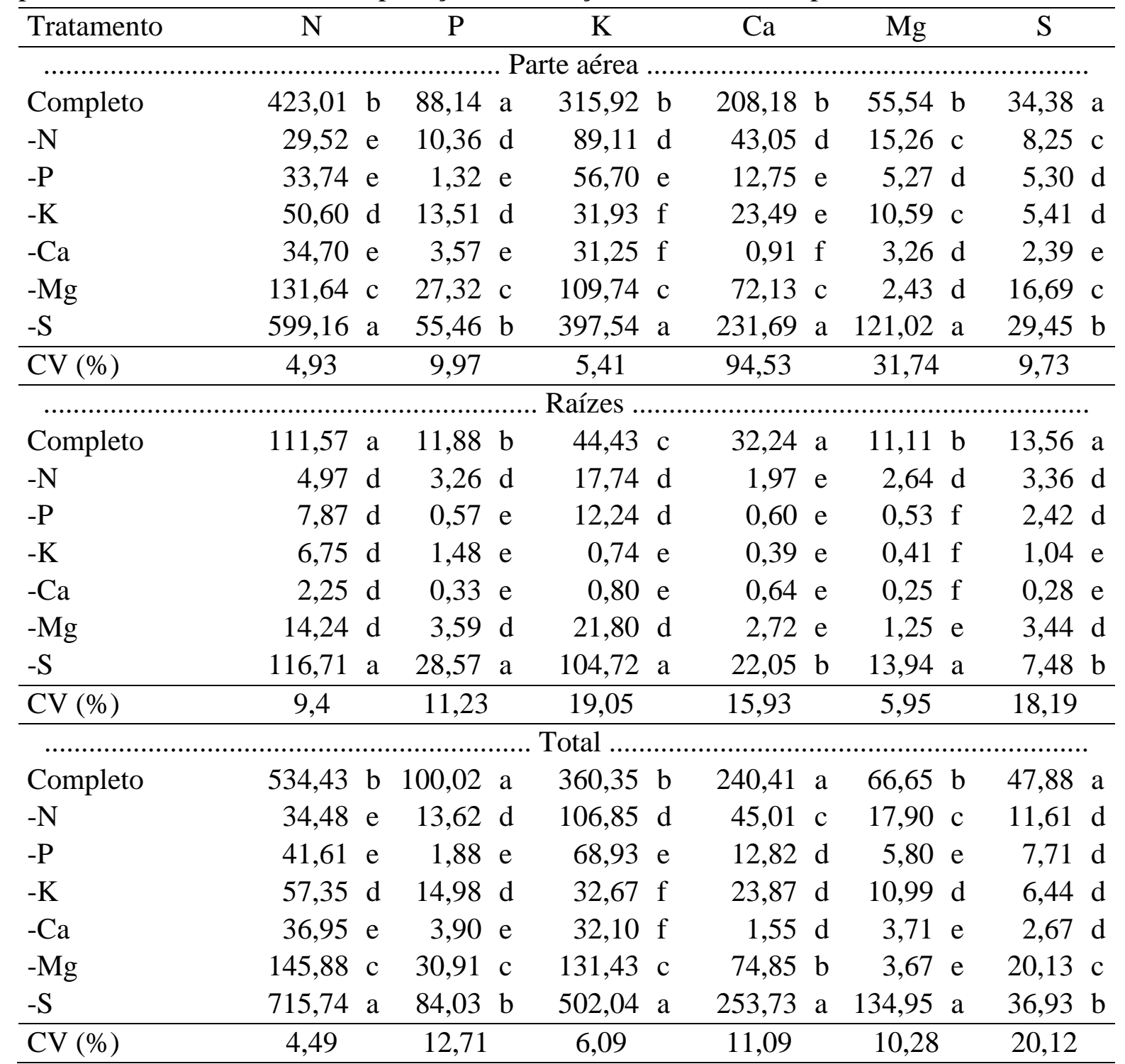

Parte aérea $=$ folha completa + caule e Total $=$ Parte aérea + raízes. Médias seguidas de mesma letra, na coluna, não diferem entre si pelo teste de Scott \& Knott a 5\%.

O maior conteúdo de nutrientes foi observado no limbo foliar, em comparação ao pecíolo, proporcionalmente à maior massa seca de cada parte da folha completa (Tabelas $1 \mathrm{e}$ 
2). As mudas de pinhão-manso submetidas à omissão do $\mathrm{N}$ apresentaram redução de crescimento e diminuição na produção de folhas. Entretanto, em função das diferenças na produção de massa seca entre os tratamentos (Tabela 1), houve diferença entre o acúmulo final de $\mathrm{N}$ nas partes da folha (Tabelas 2 e 3 ).

Os maiores acúmulos de $\mathrm{N}$ ocorreram na folha completa, (Tabela 2), apresentando ganhos de $20,75 \%$ de $\mathrm{N}$ em comparação ao tratamento completo, com maior produção de massa seca desses tratamentos em relação aos demais (Tabela 1). Os menores acúmulos de $\mathrm{N}$ foram observados nas raízes sob as omissões de $\mathrm{Ca}, \mathrm{N}, \mathrm{K}, \mathrm{P}$ e $\mathrm{Mg}$ (Tabela 3), com redução, quando comparados ao tratamento completo, de 97,98\%, 95,55\%, 93,95\%, 92,95\% e 87,24\%, respectivamente. $\mathrm{O} \mathrm{N}$ também foi o nutriente que apresentou o maior teor em todas as partes das mudas (Tabelas 2 e 3). O pinhão-manso é uma planta que apresenta elevada taxa de crescimento, sendo o $\mathrm{N}$ essencial para a assimilação de carbono e formação de novas partes na planta (TAIZ; ZEIGER, 2013), seu acúmulo foi primordial para o crescimento da espécie.

$\mathrm{O}$ acúmulo de $\mathrm{P}$ foi afetado pelas omissões de macronutrientes (Tabelas 2 e 3). Os menores teores de $\mathrm{P}$ foram observadas nos tratamentos com omissão de $\mathrm{P}$, de $\mathrm{K}$, de $\mathrm{N}$ e de $\mathrm{Ca}$ (Tabela 2). Sob omissão desses nutrientes, as mudas apresentaram redução de 99,30\%; $99,12 \%$ e $97,89 \%$ no pecíolo, respectivamente. Houveram reduções significativas de $\mathrm{P}$ também no limbo foliar, folha completa, caule, parte área, raiz e total, decorrente principalmente da omissão de N, P, K, Ca e Mg.

$\mathrm{O}$ maior acúmulo de $\mathrm{K}$ foi observado na folha completa de plantas que sofreram a omissão do S (Tabela 2). O acúmulo de K, quando houve a omissão de S, foi $29 \%$ maior que o encontrado no tratamento completo. Esses resultados foram em decorrência das elevadas produções de massa seca da folha completa no tratamento. Ao passo que, os menores acúmulos $\mathrm{K}$ foram observados no sistema radicular nos tratamentos nos quais se omitiram os elementos $\mathrm{K}$ e $\mathrm{Ca}$ (Tabela 3), em função da baixa produção de massa seca das raízes submetidas às omissões desses nutrientes e à mobilidade do $\mathrm{K}$ na planta. Além disso, a concentração dos nutrientes tende a ser pequena quando há omissão do K, porque o mesmo possui papel importante, atuando no transporte de fotoassimilados no floema (RODRÍGUEZNAVARRO; RUBIO, 2006). A deposição de biomassa é acompanhada, necessariamente, pelo acúmulo de K. Além disso, esse é um nutriente requerido na ativação de várias enzimas essenciais à síntese de compostos orgânicos (TAIZ; ZEIGER, 2013).

Os maiores acúmulos de $\mathrm{Ca}$ na folha completa foram observados no tratamento completo e na omissão de S (Tabela 2). No entanto, a omissão de Ca ocasionou redução no conteúdo desse nutriente em todas as partes das mudas de pinhão-manso, quando comparados aos demais tratamentos (Tabelas 2 e 3), sendo os menores valores encontrados na folha completa (Tabela 2). Houve redução no acúmulo de Ca na folha completa, de 99,78\%, em relação ao tratamento completo. Porém, os menores acúmulos de $\mathrm{Ca}$, de forma geral, foram observados em mudas submetidas às omissões de $\mathrm{P}$, de $\mathrm{K}$, de $\mathrm{N}$ e de Ca (Tabelas 2 e 3). $\mathrm{O}$ pecíolo foi a parte da planta que apresentou os menores conteúdos (Tabela 2), com reduções de 99,74\%; 99,57\%; 96,85\% e 99,87\% quando submetidos às omissões de $\mathrm{P}, \mathrm{K}, \mathrm{N}$ e Ca, 
respectivamente, em relação ao tratamento completo. $\mathrm{O}$ que ocorreu em função da baixa produção de massa seca apresentada pelas mudas quando submetidas a esses tratamentos.

Os menores acúmulos de $\mathrm{Mg}$ foram obtidos no pecíolo sob omissão do $\mathrm{P}, \mathrm{K}, \mathrm{Mg}, \mathrm{Ca}$ e $\mathrm{N}$ (Tabela 2), tendo em vista as baixas produções de massa seca no pecíolo nesses tratamentos (Tabela 1).

Sob influência do tratamento no qual se omitiu o $\mathrm{S}$, a folha completa foi a parte da planta que apresentou a maior teor de $\mathrm{Mg}$ (Tabela 2), 62,65\% maior que o encontrado no tratamento completo na mesma parte (Tabela 2).

A omissão do S não apresentou limitação ao crescimento das plantas, pois, nesse tratamento, as mudas apresentaram adequado crescimento e taxa de produção de massa seca (Tabela 1). Os maiores acúmulos de $\mathrm{S}$ foram observados na folha completa e no caule das mudas que receberam o tratamento completo (Tabela 2), no entanto, os resultados na folha completa quando houve omissão de $\mathrm{S}$ foram estatisticamente iguais ao tratamento completo (Tabela 2). Isso pode ter ocorrido porque algumas plantas são capazes de absorver, pelas suas folhas, o $\mathrm{S}$ nas formas do $\mathrm{SO}_{4}{ }^{-2}$ e também o $\mathrm{SO}_{2}$ do ar, ainda que de modo pouco eficiente (MALAVOLTA et al., 1997), o que também explicaria o elevado conteúdo de $\mathrm{S}$ mesmo quando a muda foi submetida à omissão desse elemento.

A omissão de $S$ favoreceu a produção de massa seca, o que foi refletido no maior acúmulo desse elemento em comparação aos demais tratamentos na folha completa (Tabela 2), demonstrando o efeito de concentração na folha completa submetida ao tratamento completo, que, mesmo produzindo menor quantidade de massa seca, apresentou resultados semelhantes ao caule (Tabelas 2 e 3). Tais resultados, corroborados pelos obtidos na análise dos demais macronutrientes e da massa seca das mudas implica em indicar que o $S$ não foi um elemento limitante ao crescimento das mudas, uma vez que, sob sua omissão, foram encontradas as maiores médias para massa seca, principalmente nas folhas e raízes (Tabela 1).

De forma geral, os maiores e os menores acúmulos de nutrientes foram observados na folha completa e no pecíolo, respectivamente (Tabelas 2 a 3), tendo a influência direta da massa seca (Tabela 1) sobre os conteúdos dos nutrientes.

A maior produção de massa seca nas mudas de pinhão-manso sob tratamento completo foi constatada no caule com $57,02 \%$ da produção de massa seca total (Tabela 4). Enquanto que, o pecíolo foi a parte da planta que apresentou a menor produção de massa seca com valores de $6,07 \%$ do total encontrado nas mudas de pinhão-manso.

As mudas de pinhão-manso apresentaram maior concentração dos macronutrientes na parte aérea em relação à raiz (Tabela 4). Os macronutrientes $\mathrm{N}, \mathrm{P}, \mathrm{Ca}$ e $\mathrm{Mg}$ apresentaram seus maiores acúmulos na folha completa com 47,3\%, 49,7\%, 52,3\% e 57,5\% e, dessa parte das mudas, 42,1, 44,1, 42,6 e 53,0\% são oriundos do limbo foliar, respectivamente. De acordo com Taiz e Zeiger (2013) isso acontece porque as folhas são os órgãos vegetativos responsáveis pela fotossíntese, respiração, transpiração das plantas, capazes de transformar

Cultura Agronômica, Ilha Solteira, v.26, n.3, p.443-455, 2017 
os nutrientes que chegam através das nervuras em fotoassimilados para as plantas, por isso boa parte dos nutrientes se encontram reservados na folha. $\mathrm{O} \mathrm{K}$ e o $\mathrm{S}$ apresentaram as maiores concentrações na região do caule, representando 56,2 e 37,5\% do total acumulado nas mudas de pinhão-manso (Tabela 4).

Tabela 4. Acúmulo (Ac.) de macronutriente $\left(\mathrm{mg} \mathrm{vaso}^{-1}\right)$ e a sua porcentagem $(\%)$ em várias partes de mudas de pinhão-manso submetidas às aplicações de soluções nutritivas completa e faltantes

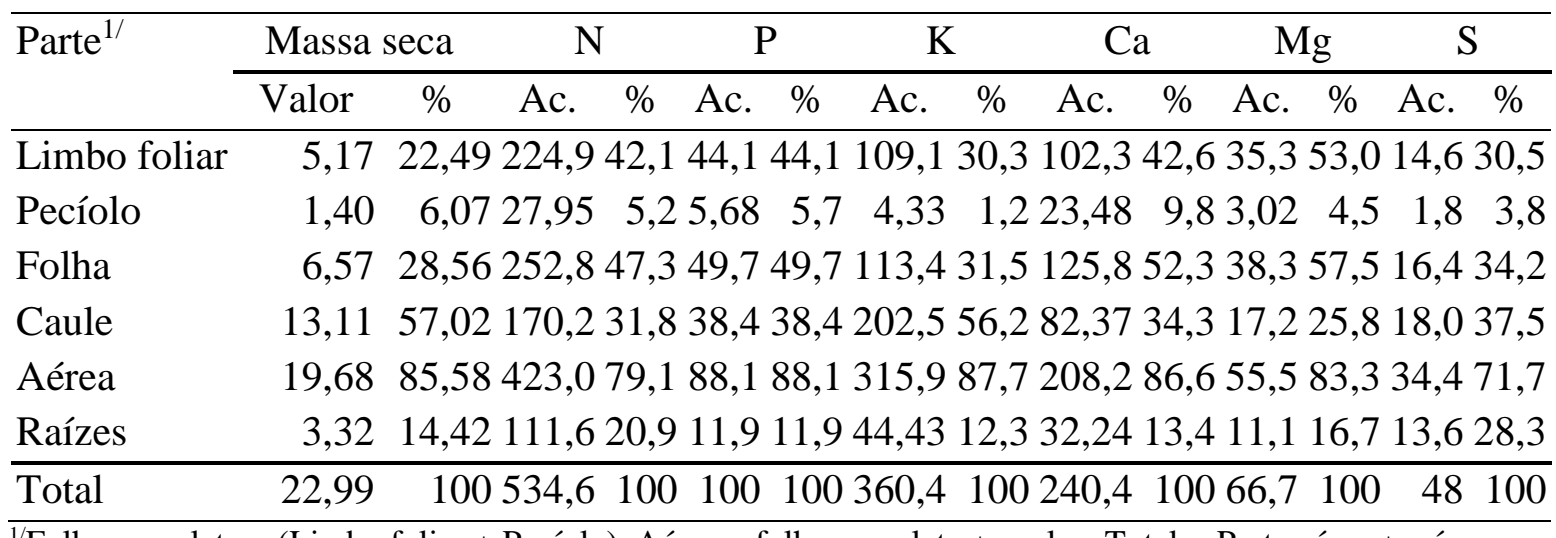

${ }^{1 /}$ Folha completa $=($ Limbo foliar + Pecíolo $)$, Aérea $=$ folha completa + caule e Total $=$ Parte aérea + raízes.

O menor acúmulo dos macronutrientes foi observado no pecíolo das folhas. Porém, nesse caso, o acúmulo de Ca foi o maior entre as médias acumuladas no pecíolo, com 9,8\% do total, enquanto o $\mathrm{K}$ apresentou a menor, com 1,2\% (Tabela 4).

$\mathrm{O}$ acúmulo de macronutrientes ocorrido em cada uma das partes das mudas de pinhãomanso seguiu a ordem: limbo foliar $=\mathrm{N}>\mathrm{K}>\mathrm{Ca}>\mathrm{P}>\mathrm{Mg}>\mathrm{S}$; pecíolo $=\mathrm{N}>\mathrm{Ca}>\mathrm{P}>\mathrm{K}>$ $\mathrm{Mg}>\mathrm{S}$; folha completa $=\mathrm{N}>\mathrm{Ca}>\mathrm{K}>\mathrm{P}>\mathrm{Mg}>\mathrm{S}$; caule $=\mathrm{K}>\mathrm{N}>\mathrm{Ca}>\mathrm{P}>\mathrm{S}>\mathrm{Mg}$; parte aérea $=\mathrm{N}>\mathrm{K}>\mathrm{Ca}>\mathrm{P}>\mathrm{Mg}>\mathrm{S}$ e raízes $=\mathrm{N}>\mathrm{K}>\mathrm{Ca}>\mathrm{S}>\mathrm{P}>\mathrm{Mg}$.

De maneira geral, o acúmulo total de macronutrientes em mudas de pinhão-manso se deu na seguinte ordem decrescente: $\mathrm{N}>\mathrm{K}>\mathrm{Ca}>\mathrm{P}>\mathrm{Mg}>\mathrm{S}$. O que foi semelhante ao descrito por Malavolta et al. (1997) que indicam, para a maioria das culturas, a seguinte exigência de macronutrientes: $\mathrm{N}>\mathrm{K}>\mathrm{Ca}>\mathrm{Mg}>\mathrm{P} \approx \mathrm{S}$.

\section{CONCLUSÃO}

1. As mudas de pinhão-manso se mostraram altamente exigentes em macronutrientes.

2. As omissões de $\mathrm{Ca}$ e de $\mathrm{K}$ foram as que proporcionaram as menores taxas de produção de massa seca para o pinhão-manso.

3. A folha completa (limbo foliar + pecíolo), de forma geral, apresentou os maiores acúmulos de nutrientes entre as partes das mudas de pinhão-manso, na seguinte sequência para os macronutrientes: $\mathrm{N}>\mathrm{Ca}>\mathrm{K}>\mathrm{P}>\mathrm{Mg}>\mathrm{S}$.

4. $\mathrm{O} \mathrm{N}$ foi o nutriente que apresentou os maiores acúmulos entre as partes das mudas, exceto no caule. Enquanto o $\mathrm{S}$ foi o macronutriente menos acumulado. 


\section{AGRADECIMENTOS}

Os autores agradecem a Coordenação de Aperfeiçoamento e Pessoal de Nível Superior (CAPES) e Fundação de Amparo à Pesquisa do Estado de Minas Gerais (FAPEMIG) pelo apoio financeiro e pelas bolsas concedidas.

\section{REFERÊNCIAS BIBLIOGRÁFICAS}

AMBROSI, D. G.; GALLA, G.; PURELLI, M.; BARBI, T.; FABBRI, A.; LUCRETTI, S.; SHARBEL, T. F.; BARCACCIA, G. DNA Markers and FCSS analyses shed light on the genetic diversity and reproductive strategy of Jatropha curcas L. Diversity, Bethesda, v. 2, n. 5, p.810-836, 2010.

BATISTA, M. M. F.; VIÉGAS, I. J. M.; FRAZÃO, D. A. C.; THOMAZ, M. A. A.; SILVA, R. C. L. Efeito da omissão de macronutrientes no crescimento, nos sintomas de deficiências nutricionais e na composição mineral em gravioleiras (Annona muricata). Revista Brasileira de Fruticultura, Jaboticabal, v. 25, n. 2, p.315-318, 2003.

CHEN, K.; REN, P.; YING, C.; JIANG, Q.; JIA, X. Genetic relationships among Jatropha curcas L. clones from Panzhihua, China as revealed by RAPD and ISSR. African Journal of Agricultural Research, Pretoria, v. 6, n. 11, p.2582-2585, 2011.

DIAS, N. S.; LIRA, R. B.; BRITO, R. F.; SOUSA NETO, O. N.; FERREIRA NETO, M.; OLIVEIRA, A. M. Produção de melão rendilhado em sistema hidropônico com rejeito da dessalinização de água em solução nutritiva. Revista Brasileira de Engenharia Agrícola e Ambiental, Campina Grande, v. 14, n. 7, p.755-761, 2010.

EPSTEIN, E.; BLOOM, A. J. Nutrição mineral de plantas: princípios e perspectivas. 2. ed. Londrina: Planta, 2006. 403 p.

HOAGLAND, D.; ARNON, D. I. The water culture method for growing plants without soil. 1. ed. Berkeley: California Agricultural Experiment Station Circular, 1950. 347 p.

LAVIOLA, B. G.; DIAS, L. D. S. Teor e acúmulo de nutrientes em folhas e frutos de pinhãomanso. Revista Brasileira de Ciência do Solo, Viçosa, v. 32, n. 5, p. 1969-1975, 2008.

LAVRES JÚNIOR, J.; BOARETTO, R. M.; SILVA, M. L. S.; CORREIA, D.; CABRAL, C. P.; MALAVOLTA, E. Deficiências de macronutrientes no estado nutricional da mamoneira cultivar Íris. Pesquisa Agropecuária Brasileira, Brasília, v. 40, n. 2, p.145-151, 2005.

LIMA, R. D. L. S.; SEVERINO, L. S.; GHEYI, H. R.; SOFIATTI, V.; ARRIEL, N. H. C. Efeito da adubação fosfatada sobre o crescimento e teor de macronutrientes de mudas de pinhão-manso. Revista Ciência Agronômica, Fortaleza, v. 42, n. 4, p.950-956, 2011.

MAIA, J. T. L. S.; BONFIM, F. P. G.; GUANABENS, R. E. M.; TRENTIN, R.; MARTINEZ, H. E. P.; PEREIRA, P. R. G.; FONTES, P. C. R. Omissão de nutrientes em plantas de pinhãomanso cultivadas em solução nutritiva. Revista Ceres, Viçosa, v. 61, n. 5, p.723-731, 2014. 
MALAVOLTA, E. Diagnose foliar. In: MALAVOLTA, E. (ed.). Manual de nutrição mineral de plantas. São Paulo: Agronômica Ceres, 2006. cap. 8, p. 568-631.

MALAVOLTA, E.; VITTI, G. C.; OLIVEIRA, S. A. 1997. Avaliação do estado nutricional das plantas: princípios e aplicações. 1. ed. Piracicaba: Potafos, 1997. 319 p.

MARQUES, T. C. M.; CARVAlHO, J. G.; LACERDA, M. P. C.; MOTA, P. E. F. 2004. Crescimento inicial do paricá (Schizolobium amazonicum) sob omissão de nutrientes e de sódio em solução nutritiva. Cerne, Lavras, v. 10, n. 2, p.184-195, 2004.

MATOH, T.; KOBAYASHI, M. Boron and calcium, essential inorganic constituents of pectic polysaccharides in higher plant cell walls. Journal of Plant Research, Tokyo, v. 11, n. 1, p.179-190, 1998.

NEVES, M. B.; BUZETTI, S.; CASTILHO, R. M. M.; BOARO, C. S. F. Desenvolvimento de plantas de girassol ornamental (Helianthus annuus L.) em vasos, em dois substratos com solução nutritiva e em solo. Científica, Jaboticabal, v. 33, n. 2, p.127-133, 2005.

NUNES, C. F. Caracterização de frutos, sementes e plântulas e cultivo de embriões de pinhão-manso (Jatropha curcas L.). 2007. 78 f. Dissertação (Mestrado em Agronomia Fitotecnia) - Universidade Federal de Lavras, Lavras, 2007.

OLIVEIRA, E. L.; FARIA, M. A.; EVANGELISTA, A. W. P.; MELO, P. C. 2012. Resposta do pinhão-manso à aplicação de níveis de irrigação e doses de adubação potássica. Revista Brasileira de Engenharia Agrícola e Ambiental, Campina Grande, v. 16, n. 6, p.593-598, 2012.

OVANDO-MEDINA, I.; ESPINOSA-GARCÍA, F. J.; NUNTILDE, J. S.; SALVADORFIGUEROA, M. State of the art of genetic diversity research in Jatropha curcas. Scientific Research and Essays, Victoria, v. 6, n. 8, p.1709-1719, 2011.

RODRÍGUEZ-NAVARRO, A.; RUBIO, F. High-affinity potassium and sodium transport systems in plants. Journal of Experimental Botany, Oxford, v. 57, n. 5, p.1149-1160, 2006.

SHIMAZAKI, K.; DOI, M.; ASSMANN, S. M.; KINOSHITA, T. Light regulation of stomatal movement. Annual Review of Plant Biology, Danvers, v. 58, n. 1, p.219-247, 2007.

SILVA, E. B.; TANURE, L. P. P.; SANTOS, S. R.; RESENDE JÚNIOR, P. S. Sintomas visuais de deficiências nutricionais em pinhão-manso. Pesquisa Agropecuária Brasileira, Brasília, v. 44, n. 4, p.392-397, 2009.

SINGH, R. A.; KUMAR, M.; HAIDER, E. Synergistic cropping of summer groundnut with Jatropha curcas - A new two-tier cropping system for Uttar Pradesh. Journal of SAT Agricultural Research, Medak, v. 5, n. 1, p.1-2, 2007.

TAIZ, L.; ZEIGER, E. Plant physiology. 5. ed. California: The Benjamin/Cummigs Publishing, 2013. 559 p.

WANG, H. Z.; FENG, S. G.; LU, J. J.; SHI, N. N.; LIU, J. J. Phylogenetic study and

Cultura Agronômica, Ilha Solteira, v.26, n.3, p.443-455, 2017 
molecular identification of 31 Dendrobium species using inter-simple sequence repeat (ISSR) markers. Scientia Horticulturae, Amsterdam, v. 122, n. 3, p.440-447, 2009. 